\title{
A Dynamic Theory of Lending Standards*
}

\author{
Michael J. Fishman \\ Northwestern
}

\author{
Jonathan A. Parker \\ MIT and NBER
}

\author{
Ludwig Straub \\ Harvard
}

\author{
Preliminary and incomplete \\ February 15, 2019
}

\begin{abstract}
We develop a dynamic model of credit markets in which both lending standards and the quality composition of the borrower pool are endogenous. Borrowers can be of high or low quality, and each lender privately decides on its lending standard, modeled as a technology that screens out low types with cost proportional to the probability of detection. Lending standards are dynamic strategic complements: tighter screening worsens the future pool of borrowers, increasing the incentive to screen in the future. The equilibrium is unique, but may exhibit two stable steady states, one with loose lending standards and one with tight lending standards. Thus, even temporary adverse shocks can have amplified and long-lasting effects on the health of credit markets. According to the model's normative predictions, lending standards are inefficiently tight during such episodes, since banks do not internalize the effect of tighter standards on the quality of the borrower pool. We discuss several policies such as government support for lending that can help ameliorate this inefficiency, along with several pitfalls to avoid.
\end{abstract}

JEL codes: D82, G21, G01, G10

Keywords: Lending standards; Credit cycle; Strategic complementarity; Amplification; Persistence; Policy response

\footnotetext{
*We thank Andrew Winton and participants at the MIT Macro Lunch and the Minnesota Corporate Finance Conference for comments on early slides. Ludwig Straub appreciates support from the Macro-Financial Modeling Group. Fishman: Kellogg School of Management, Northwestern University, 2211 Campus Drive, Evanston, IL 60208, e-mail: M-Fishman@Kellogg.Northwestern.edu; Parker: Sloan School of Management, MIT, 100 Main Street, Cambridge, MA 02142-1347, JAParker@MIT.edu; Straub, Department of Economics, Harvard University, 1805 Cambridge St, Cambridge, MA 02138, LudwigStraub@fas.harvard.edu.
} 


\section{Introduction}

The profitability of originating a loan, or any other claim on future cash flows, inherently depends on the quality of the borrower who is seeking to raise external financing. As a result, banks have an incentive to impose lending standards to avoid lending to borrowers that are unlikely to repay. Thus, lending standards determine the equilibrium allocation of credit, influencing lending volumes, interest rates, and the quality of borrowers. The prominent role of lending standards came to the fore during the credit boom-bust cycle of the 2000s, with lax lending standards leading up to the financial crisis, and tight lending standards during the sluggish recovery after that. Yet, what drives lending standards? Do lending standards have a role to play in explaining credit-driven boom-bust cycles? Can lending standards be "too lax" or "too tight," calling for governments regulation?

In this paper we propose a dynamic model of lending standards that speaks to these questions. The model highlights two properties of lending standards that are crucial to understanding their equilibrium usage, their dynamic effects, and their welfare implications. First, lending standards are dynamic strategic complements. Borrowers whose loan applications were declined at one bank may seek further applications at another one later. Thus, when the first bank tightens lending standards, the later one is confronted with a more adversely selected pool, raising the incentive to follow suit and tighten standards as well. Second, such tight lending standards have negative externalities. Even with tight lending standards in place, the later bank may unknowingly lend to low-quality borrowers that were previously declined and thus fund negative net present value projects. Since this is a social cost that is not internalized by any individual bank, government interventions to prevent excessively tight lending standards can be beneficial. We show that interventions early in a boom-bust cycle are preferred to later ones, but if interventions come too late, they can hurt welfare, rather than improve it.

Our model consists of a mass of competitive banks and a pool of potential borrowers, which are initially identical conditional on public or readily available information (e.g. identical within credit score brackets). Each instant, borrowers are drawn from the pool and approach banks in search of a loan to fund an investment project. Projects differ by the type of borrower, and can either be of high or low quality, implying a positive or negative net present value.

We conceptualize lending standards as the extent to which lenders expend effort to screen a borrower by creating private information about the future payoff of lending to that borrower before deciding whether or not to originate a loan. Provided the typical loan has positive net present value, a bank can lend with lax lending standards. Alternatively, a bank may choose tight lending standards and screen borrowers so as to identify low-quality borrowers and avoid making loans for their projects. By rejecting low-quality borrowers, a bank with tighter lending standards worsens the pool of potential borrowers for all banks in the future. Thus the current quality of potential borrowers reflects past lending standards. At the same time, lending standards depend on the current quality of potential borrowers: the larger the share of low-quality borrowers in the pool, the more valuable it is for banks to screen and tighten lending standards. 
Our model makes the following five main contributions.

First, markets with the same set of fundamentals may see persistently different trajectories in equilibrium lending standards, depending on their specific history (i.e. their initial conditions). This idea is reflected in the fact that the model gives rise to multiple steady states in the single state variable in our model - the share of high-quality potential borrowers in the pool, the pool quality. This multiplicity is a consequence of the strategic complementarity inherent to the choice of lending standards. When the pool quality is high, banks do not find it worth trying to detect the occasional low-quality potential borrower, and loose lending standards are optimal, which do not reduce the quality of the pool. When the pool quality is low, however, banks find it worthwhile to screen potential borrowers and so reject many low-quality borrowers and so contribute to a low pool quality. Accordingly, in the steady state with loose lending standards ("pooling steady state"), the loan volume is high and loan spreads are low. In the steady state with tight lending standards ("screening steady state"), the loan volume is low and loan spreads are high. Interestingly, despite the multiplicity in steady states we prove that there exists a unique equilibrium, avoiding any ambiguity in the model's equilibrium predictions.

Second, as a result of steady state multiplicity, temporary changes in borrower quality can lead to persistent, or even permanent, shifts in lending standards and loan volumes. In particular, between the two stable steady states, there is a threshold pool quality: below the threshold, the pool quality deteriorates until the screening steady state is reached; above the threshold, the market improves and converges to the pooling steady state. In this setting, a temporary change in market fundamentals-e.g. shifts in the payoff structure of borrowers' projects or the share of good borrowers entering the pool—can set in motion a self-reinforcing dynamic culminating in a permanent shift in the credit market equilibrium. Thus, absent interventions or changes in market fundamentals of the opposite sign, lending standards introduce sluggishness in the reaction of credit markets to fluctuations in fundamentals.

Third, markets with lending standards can exhibit credit rationing, which slows the speed of transitional dynamics even further. In our model, credit rationing can only occur during recoveries, when the pool quality is set to improve over time as the credit market converges back to the pooling steady state. The logic behind credit rationing in our model is quite different from the typical credit rationing due to adverse selection (Stiglitz Weiss 1981, Mankiw 1986). If the pool quality is set to improve rapidly over time, borrowers that have not been previously rejected have an incentive to delay loan applications with the prospect of cheaper lending rates down the road. With these relatively high-quality borrowers staying out of the market, however, banks would find it unprofitable to lend. In equilibrium, these two forces have to balance, with banks not lending to all possible borrowers, and relatively high-quality borrowers being indifferent between delaying or not. Since the natural "thawing" of frosty credit markets is slowed down in this region, we call this phenomenon slow thawing.

Fourth, the two steady states can be Pareto-ranked. The planner always prefers the pooling equilibrium. The key to this ranking is the negative externality associated with tight lending 
standards: screening and rejection decisions are a bank's private information, and in making these decisions, each bank ignores its effects on the quality of the pool of potential borrowers. ${ }^{1}$

Fifth, motivated by this externality, there is an important role for government interventions in credit markets with lending standards. To characterize optimal policy, we study the dynamic planning problem of a planner choosing the optimal path of lending standards. We characterize the optimal policy concisely by a social threshold quality, above which the planner prefers pooling and below which the planner prefers screening. Our main result here is that the social threshold always lies strictly below the private threshold. We argue that this has far-reaching implications for the regulatory response to transitory negative changes in fundamentals of different magnitudes. For a decline in pool quality that is relatively mild, no intervention is needed, as the private threshold is not crossed. However, for large enough declines in the quality of the pool, the optimal response is an intervention that ensures that banks do not screen and that credit standards remain loose. Such interventions involve short-run costs and long-run benefits through improvements in the pool of potential borrowers. Because the pool of potential borrowers is a common resource, there is no way for individual banks to recover the costs from later profits absent collective, i.e. government, actions.

Further, we show that the short-run costs are larger the later an intervention occurs, so that early timing of interventions becomes crucial. In fact, if a government waits so long before intervening that the pool quality has fallen below the social threshold, interventions become detrimental to welfare. As we argue below, in such a scenario, governments missed the window to act and should focus on structural reforms of the lending market instead, such as reforms to the credit reporting system.

Related literature. Our paper sits at the intersection of two literatures. One exploring the role of lending standards, or information acquisition more broadly, in a static context; and the other studying dynamic adverse selection economies without information acquisition.

Among papers in the former literature, Bolton, Santos and Scheinkman (2015) and Fishman and Parker (2015) identify a strategic complementarity in information acquisition that is conceptually similar to ours. They do so in a static model where rejected borrowers can approach a second lender, and where the complementarity manifests itself in multiple equilibria. Due to the static nature of these models, however, they cannot address the evolution of lending standards over time, which is the focus of the current paper. This intertemporal aspect of our model shapes the equilibrium behavior (e.g. the multiplicity in steady states but uniqueness of equilibrium) as well as the policy prescriptions (e.g. the optimal timing of interventions).

Ruckes (2004) and Dell'Ariccia and Marquez (2006) also propose static models of lending standards but neither features the strategic complementarity we emphasize. In Ruckes (2004),

\footnotetext{
${ }^{1}$ It is worth noting that in our model, lending standards do not influence the quality of new potential borrowers entering the pool of potential borrowers, which we take to be exogenous. For a model that endogenizes this margin, see $\mathrm{Hu}$ (2018).
} 
lenders simultaneously evaluate a borrower and lending standards are strategic substitutes. This difference follows because in his model, if a borrower is rejected or quoted a high interest rate, the borrower cannot then seek out other potential lenders. In Dell'Ariccia and Marquez (2006), tight lending standards come in the form of requiring the (costly) posting of collateral. In their model, lending standards are strategically neutral, generating a unique equilibrium.

Among papers studying dynamic adverse selection models without information acquisition, the most relevant to us are Daley Green (2012, 2015), Malherbe (2015), Zrymov (2015) and Caramp (2017). Daley Green $(2012,2015)$ and Malherbe (2015) propose models where current markets can break down when high-quality sellers remain absent waiting for market prices to improve over time. This mechanism is related to, but distinct from, our slow thawing dynamics. In these models, the path of market prices over time separates good sellers from bad. In our slow thawing dynamics, the equilibrium composition of borrowers does not change, only the speed of lending is reduced. Zrymov (2015) and Caramp (2017) study models where bad sellers strategically enter when market prices are good. This, in and of itself, does not lead to a market shutdown (lower prices positively select entrants), but as Caramp (2017) emphasizes, the larger presence of bad sellers can raise the likelihood of adverse selection induced market failures in the future.

Perhaps most closely related is $\mathrm{Hu}$ (2018), who also studies a dynamic model in which banks choose lending standards and the quality of the borrower pool evolves over time. The key difference is that in his analysis, lending standards are strategic substitutes, due to the positive response of the average quality of newly entering borrowers to tighter lending standards. In this context, $\mathrm{Hu}(2018)$ finds a number of interesting results regarding economic recoveries, e.g., his model may exhibit double dip recoveries.

\section{A Model of Lending Standards}

Time is continuous and runs from $t$ to infinity, $t \in[0, \infty)$. There are two sets of agents: a unit mass of potential borrowers who have no capital and are looking to fund projects and a large mass $\mathcal{J}$ of competitive banks. All agents are risk neutral and have discount rate $r>0$. The main state variable in the model is the quality composition of the pool of borrowers, defined below and denoted by $x_{t}$, which both determines and is influenced by the main control variables, banks' lending standards, denoted by $z_{j t}$, which will turn out to be identical across banks in equilibrium.

\section{Borrowers and banks}

Borrowers. At Poisson rate $\kappa>0$, a potential borrower receives an investment opportunity. This opportunity is a project that requires an up-front investment of 1 . Borrowers have no capital and must fund the investment externally. If the borrower raises the funds and makes the up-front investment at time $t$, then the project returns both a pledgeable cash flow at time $t+T$ and a non-pledgeable private benefit $u>0$ (in present value) to the borrower. With this private benefit all 
borrowers will have the incentive to finance their project, even if they know they will receive no monetary benefit.

To capture differences in borrower quality, we assume that there are two types of borrowers: type $H$ ("high quality") and type $L$ ("low quality"). Based on the pledgeable cash flow, type- $H$ borrowers always have positive NPV investment opportunities. That is, the pledgeable cash flow of a type- $H$ borrower's project is $D_{H}$, with gross return $R_{H} \equiv e^{-r T} D_{H}>1$. Type- $L$ borrowers always have negative NPV projects, with pledgeable cash flow $D_{L}$ and gross return $R_{L} \equiv e^{-r T} D_{L}<1$. A borrower's type is permanent, always type $H$ or always type $L$. We refer to $\rho \equiv \frac{R_{H}-R_{L}}{1-R_{L}}>0$ as the (normalized) return spread between the investments of the two types.

When an investment opportunity arises, borrowers choose whether or not to apply to the competitive banking sector for a unit of funding to implement their project. A borrower that applies for funding is either approved or denied depending on whether she satisfies the bank's lending standards. If a borrower is funded, she invests in her project, exits the pool to run the project, and is immediately replaced in the pool by a new potential borrower. Alternatively, if the borrower does not apply for funding or is denied funding, she returns to the pool where at rate $\kappa>0$ a new investment opportunity arises. Borrowers in the pool "die" at Poisson rate $\delta>0$ and they leave the pool. Interpret these borrowers as ones who will no longer receive investment opportunities. New borrowers enter the pool at rate $\delta$. New borrowers arrive as type $H$ with exogenous probability $\lambda$ and as type $L$ with probability $1-\lambda$.

These assumptions imply that the size of the pool is constant at 1 . As a result, it will suffice to keep track of the fraction of type- $H$ borrowers in the pool of potential borrowers at time $t, x_{t} \in[0,1]$. We allow for fluctuations in the size of the pool of borrowers in Section 6.

Finally, we assume throughout that the average project of a borrower entering the pool has positive NPV based on the pledgeable cash flow.

Assumption 1. The average investment project has a positive net present value $\lambda R_{H}+(1-\lambda) R_{L}>1$.

Banks and lending standards. Banks make two decisions. First, they decide whether to be active or inactive. Second, conditional on being active, they choose their lending standard, that is, how aggressively to screen potential borrowers.

At any instant $t$, a bank may choose to be active, in which case it enters a competitive lending market, where it may receive a loan application by a borrower. Alternatively a bank may choose to be inactive in which case it makes no loans and consequently receives no loan applications. Let $\theta_{j t}$ denote the probability that bank $j$ is active at time $t$. While generally all banks are active in our model, e.g. at all steady-states where $x=$ const, there may be a region in the state space with equilibrium credit rationing, $\theta_{j t}<1$, where banks offer fewer loans than borrowers demand.

An active bank $j$ also chooses a lending standard $z_{j t} \in[0, \bar{z}]$, where $\bar{z} \in[0,1]$. With lending standard $z_{j t}$, a type- $L$ borrower is identified as such with probability $z_{j t}$, in which case her loan is denied. Otherwise, the borrower's loan is approved. A type- $H$ borrower is never misidentified as a 
type $L$, an assumption that is relaxed in Section ??. But with imperfect borrower screening, $z_{j t}<1$, some type- $L$ borrowers get financed. A bank's cost of utilizing the lending standard $z_{j t}$ is $\tilde{c} z_{j t}$, where $c \equiv \frac{\tilde{c}}{1-R_{L}}>0$ is the (normalized) marginal cost. The most lax lending standard corresponds to $z_{j t}=0$, in which case all loan applications are deemed to meet the lending standards of bank $j$. Banks choose lending standards to maximize expected profit. Given a lending standard $z_{j t}$, banks offer to lend 1 in exchange for a promised loan payment at time $t+T$ equal to $D_{j t}$.

Due to symmetry and competition, it is without loss of generality to assume that all banks choose the same probability of being active, $\theta_{t}$, the same lending standard $z_{t}$, and the same loan payment $D_{t}$. With a loan face value of $D_{t}$, repayment is $\min \left\{D_{t}, D\right\}$, where $D$ is the payoff on the investment, $D_{L}$ or $D_{H}$ depending on borrower type. Since type- $L$ borrowers have negative NPV investments, $D_{t}>D_{L}$ for a bank to break even in expectation. Thus, type- $L$ borrowers always default. The repayment $D_{t}$ is without loss of generality bounded above by $D_{H}$ since any higher $D_{t}$ will not generate additional repayment. So if a loan is made (meaning the bank can break even) then type- $H$ borrowers will not default. We define $R_{t} \equiv e^{-r T} D_{t}$ as the credit spread charged by the bank since $r+\frac{1}{T} \ln R_{t}$ is per-period interest rate on the loan. $R_{t}$ always lies in $\left(R_{L}, R_{H}\right)$.

Information structure. Before screening, banks cannot distinguish between type- $H$ and type- $L$ borrowers. ${ }^{2}$ Borrowers have no private information about their type when they enter the pool. And for as long as a borrower has no such private information, we call her an average borrower. Some type- $L$ borrowers learn that they are type- $L$ after being denied funding by a bank because of a failure to meet the lending standard. We call these borrowers rejected borrowers. ${ }^{3}$ The shares of average and rejected borrowers are endogenously determined. For instance, the lower the lending standard $z_{t}$, the fewer rejected borrowers are in the pool. All agents have common knowledge of the structural parameters of the lending market and the initial fraction of type- $H$ borrowers in the pool, $x_{0}$. Also, all agents can infer past, current, and future $x_{t}$.

\section{A borrower's problem}

Taking the path of credit spreads $\left\{R_{t}\right\}$ as given, borrowers with investment opportunities choose whether to apply for a loan at each time $t$. Let $\varphi_{t}^{a}$ denote the probability that an average borrower with an investment opportunity applies for a loan-as opposed to waiting in hope of an improvement in borrowing opportunities. Let $\varphi_{t}^{r}$ denote the probability that a rejected borrower with an investment opportunity applies for a loan. Letting $J_{t}^{a}$ and $J_{t}^{r}$ denote the value functions of an average borrower and a rejected borrower, respectively, the optimal strategies for the two satisfy

\footnotetext{
${ }^{2}$ Observe that for each individual bank, previously screened loan applicants will represent a zero mass in the pool of borrowers and can therefore be ignored.

${ }^{3}$ Thus there are three types of borrowers in the pool at any time: average borrowers who are actually type $H$, average borrowers who are actually type $L$, and rejected borrowers (always type $L$ ). We show however that optimal behavior depends only on the share of type- $H$ borrowers, $x_{t}$, because the behavior of all type- $L$ borrowers is the same.
} 
the following Hamilton-Jacobi-Bellman equations:

$$
\begin{gathered}
r J_{t}^{a}=\max _{\varphi_{t}^{a} \in[0,1]} \kappa \theta_{t} \varphi_{t}^{a}\left\{\lambda\left(R_{H}-R_{t}+u\right)+(1-\lambda)\left(1-z_{t}\right) u+(1-\lambda) z_{t} J_{t}^{r}-J_{t}^{a}\right\}+\dot{J}_{t}^{a}-\delta J_{t}^{a} \\
r J_{t}^{r}=\max _{\varphi_{t}^{r} \in[0,1]} \kappa \theta_{t} \varphi_{t}^{r}\left\{\left(1-z_{t}\right)\left(u-J_{t}^{r}\right)\right\}+\dot{J}_{t}^{r}-\delta J_{t}^{r}
\end{gathered}
$$

where $J_{t}^{a}$ and $J_{t}^{r}$ satisfy the transversality conditions $\lim _{t \rightarrow \infty} e^{-(r+\delta) t} J_{t}^{a}=\lim _{t \rightarrow \infty} e^{-(r+\delta) t} J_{t}^{r}=0$. For an average borrower, (1a) reflects three possible outcomes that may occur when she has an investment opportunity, is matched with an active bank, and chooses to apply for financing: with probability $\lambda$ she is type $H$ and is funded, receiving a monetary payoff of $R_{H}-R_{t}$ and $u$ in private benefits; with probability $(1-\lambda)\left(1-z_{t}\right)$, she is type $L$ but satisfies the lending standard, receiving a payoff of $u$ in private benefits; and with probability $(1-\lambda) z_{t}$, she is type $L$ and does not satisfy the lending standard (is rejected), receiving a payoff of $J_{t}^{r}$. For a rejected borrower who is has an investment opportunity and is matched with an active bank, (1b) reflects the fact that with probability $1-z_{t}$, she satisfies the lending standard and receives a payoff of $u$ in private benefits; otherwise, she continues as a rejected borrower.

With strategies $\left\{\varphi_{t}^{a}, \varphi_{t}^{r}\right\}$, there is a flow of

$$
\kappa_{H t} \equiv \kappa \varphi_{t}^{a} x_{t}
$$

type- $H$ borrowers applying for loans. Note that all of the type- $H$ borrowers belong to the sub-pool of average borrowers. There is a flow of

$$
\kappa_{L t} \equiv \kappa \varphi_{t}^{a} \frac{1-\lambda}{\lambda} x_{t}+\kappa \varphi_{t}^{r} \frac{\lambda-x_{t}}{\lambda}
$$

type- $L$ borrowers applying for loans. For the derivation of (3), let $A_{t}$ denote the share of average borrowers at time $t$, with $1-A_{t}$ being the share of rejected borrowers at time $t$. The fraction of type- $H$ borrowers in the whole pool is $x_{t}=A_{t} \lambda$. The flow of type- $L$ borrowers equals $\kappa \varphi_{t}^{a} A(1-$ $\lambda)+\kappa \varphi_{t}^{r}(1-A)$. Substituting in $A_{t}=x_{t} / \lambda$ yields (3). In equilibrium, it will be the case that $\varphi_{t}^{a}=\varphi_{t}^{r}=1$, so that $\kappa_{H t}=\kappa x_{t}$ and $\kappa_{L t}=\kappa\left(1-x_{t}\right)$.

\section{A bank's problem}

Since there is a flow $\kappa_{H t}+\kappa_{L t}$ of loan applications by borrowers at time $t$, it is without loss to assume that there are at most a flow of $\kappa_{H t}+\kappa_{L t}$ active banks at time $t$. As will be seen below, there are cases where some banks remain inactive in equilibrium, leaving only $\theta_{t}\left(\kappa_{H t}+\kappa_{L t}\right)$ active banks, with $\theta_{t} \in[0,1]$. A fraction $\theta_{t}$ of the flow $\kappa_{H t}+\kappa_{L t}$ of loan applications is then received by the $\theta_{t}\left(\kappa_{H t}+\kappa_{L t}\right)$ active banks. 
Conditional on flows $\kappa_{H t}, \kappa_{L t}$ and credit spread $R_{t}$, an active bank's lending standard $z$ solves

$$
\Pi_{t}\left(R_{t}\right) \equiv \max _{z \in[0, \bar{z}]} \kappa_{H t}\left(R_{t}-1\right)+\kappa_{L t}(1-z)\left(R_{L}-1\right)-\left(\kappa_{H t}+\kappa_{L t}\right) \tilde{c} z
$$

Taking $z$ as given, Bertrand competition among banks then determines $R_{t}$ by

$$
\Pi_{t}\left(R_{t}\right)=0
$$

Whenever this cannot be satisfied by any finite $R_{t}$, no bank will find it profitable to lend. In this case, we set $R_{t}=\infty$ and $\theta_{t}=0$.

\section{Evolution of the borrower pool}

The evolution of the quality of the borrower pool is given by

$$
\dot{x}_{t}=\theta_{t} \kappa_{L t}\left(1-z_{t}\right) \lambda-\theta_{t} \kappa_{H t}(1-\lambda)+\delta\left(\lambda-x_{t}\right),
$$

which is the combination of three distinct forces: the first term accounts for the $\theta_{t} \kappa_{L t}\left(1-z_{t}\right)$ type- $L$ borrowers who are funded and replaced with a fraction $\lambda$ of type- $H$ borrowers; the second term accounts for the $\theta_{t} \kappa_{H t}$ type- $H$ borrowers who are funded and replaced with a fraction $1-\lambda$ of type- $L$ borrowers; and the third term accounts for the $\delta \lambda$ type- $H$ borrowers being born and $\delta x_{t}$ borrowers dying each instant.

\section{Equilibrium}

We define an equilibrium as follows:

Definition 1. Given an initial share of type- $H$ borrowers $x_{0} \in[0,1]$ in the pool, an equilibrium consists of a path of the fraction of type- $H$ borrowers $\left\{x_{t}\right\}$, credit spreads $\left\{R_{t}\right\}$, shares of active banks $\left\{\theta_{t}\right\}$, borrowers' application decisions $\left\{\varphi_{t}^{a}, \varphi_{t}^{r}\right\}$, implied application flows of type- $H$ and type- $L$ borrowers $\left\{\kappa_{H t}, \kappa_{L t}\right\}$, and screening choices $\left\{z_{t}\right\}$ such that

- $\left\{\varphi_{t}^{a}, \varphi_{t}^{r}\right\}$ solve each type's maximization problem (1) given $\left\{R_{t}, z_{t}, \theta_{t}\right\}$,

- $\left\{\kappa_{H t}, \kappa_{L t}\right\}$ are determined by (2) and (3),

- $z_{t}$ solves the bank's maximization problem (4) given $\left\{R_{t}, \kappa_{H t}, \kappa_{L t}\right\}$,

- $R_{t}$ is determined by the zero profit condition for banks (5) given $\kappa_{H t}, \kappa_{L t}$ whenever possible; if not, $R_{t}=\infty$ if $\kappa_{H t}=0$,

- $\left\{x_{t}\right\}$ follows the law of motion (6), 
- all banks enter, $\theta_{t}=1$, if a marginal inactive bank could make positive profits from lending, which is the case if average borrowers strictly prefer a loan today,

$$
\lambda\left(R_{H}-R_{t}+u\right)+(1-\lambda)\left(1-z_{t}\right) u+(1-\lambda) z_{t} J^{r}-J^{a}>0,
$$

the interest rate is below the largest rate $R_{t}<R_{H}$; no banks enter, $\theta_{t}=0$, if $\kappa_{H t}=0$; and $\theta_{t} \in(0,1]$ if banks are indifferent between lending and not which is the case when (7) holds with equality.

A steady state (equilibrium) is an equilibrium in which all equilibrium objects $\left\{x_{t}, R_{t}, \theta_{t}, \varphi_{t}^{a}, \varphi_{t}^{r}, z_{t}\right\}$ are constant over time.

To focus on a parameter range where these model elements matter, we impose the following assumption:

Assumption 2. The cost of bank screening $c$ is not too low or too high:

$$
1-\lambda<c<1-x^{\mathcal{S}}+\bar{z}^{-1} \min \left\{x^{\mathcal{s}} \rho-1,0\right\}
$$

where $x^{\mathcal{S}}=\lambda-\lambda \frac{(1-\lambda) \bar{z}}{(1-\lambda \bar{z})+\delta \kappa^{-1}}$.

The first inequality in Assumption 2 ensures that the bank screening cost $\tilde{c}$ is high enough that tight lending standards do not strictly dominate loose lending standards. The second inequality ensures that there can exist a steady state in which tight lending standards are optimal. Assumption 2 is made throughout the remainder of this paper.

\section{Equilibrium characterization}

The model's tractability allows for a tight analytical characterization of the set of equilibria, starting with steady-state equilibria.

\subsection{Steady-state equilibria}

Borrowers' and banks' behavior simplifies significantly in a steady-state equilibrium. ${ }^{4}$ Borrowers, facing the same interest rate $R_{t}=R$ at all times, have no incentive to wait and therefore choose $\varphi_{t}^{a}=\varphi_{t}^{r}=1$. In fact, they strictly prefer borrowing to waiting, as in (7), which is why all banks prefer to be active in a steady state, $\theta=1$. This follows because, for any bank to be active, the loan rate needs to be weakly below the highest pledgeable payoff, $R \leq R_{H}$, but then $J^{a}>0$, which is equivalent to (7) in a steady state.

\footnotetext{
${ }^{4}$ Since prices and quantities are constant, we drop the time subscripts for this subsection.
} 
Figure 1: The two forces shaping steady-state equilibria.

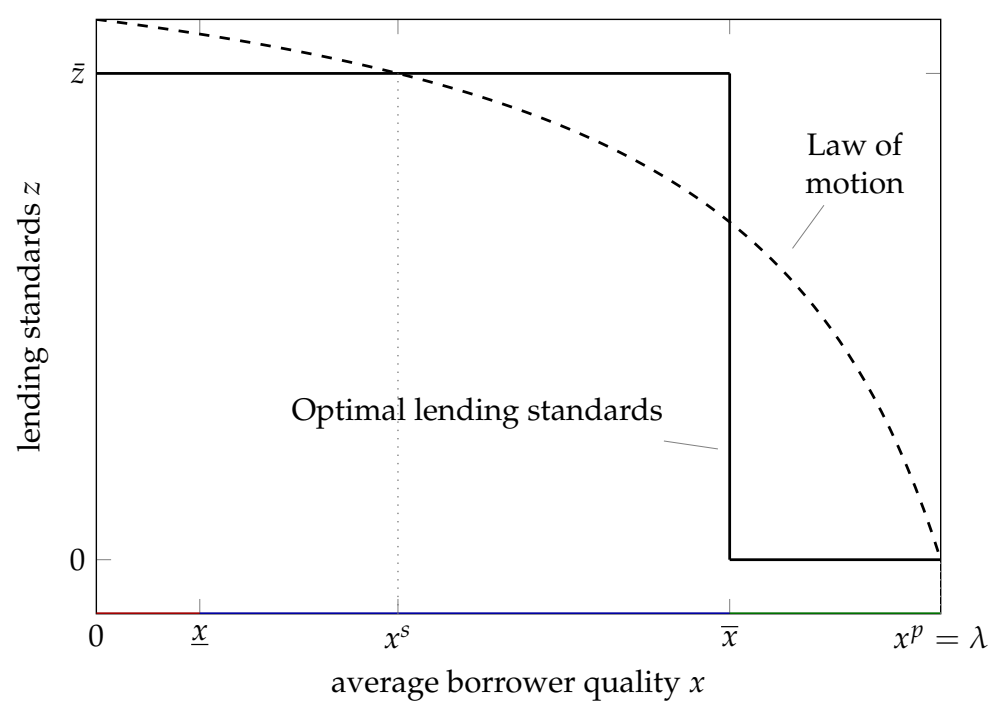

Note: This figure shows two curves whose intersections yield the steady-state pool quality $x$ and the steady-state lending standard $z$. The solid line represents the optimal choice of the lending standard, (9). The dashed line represents the pool quality $x$ that is caused by any given lending standard $z$ through the law of motion.

The steady-state quality of the pool $x$ and the steady-state lending standard $z$ are jointly determined, by the interaction of two forces. On the one hand, the law of motion of $x,(6)$, implies that when $\dot{x}=0$,

$$
x=\lambda-\lambda \frac{(1-\lambda) z}{(1-\lambda z)+\delta \kappa^{-1}} .
$$

This equation highlights that tighter lending standards - higher $z$ - are associated with a lower steady-state quality of the pool of borrowers $x$. This effect is greater when the effects of lending standards on the pool are more persistent (low death rate $\delta$ ) or when opportunities to invest arise more frequently (high $\kappa$ ) and so potential investors are evaluated more frequently.

On the other hand, banks solve (4) and choose tighter lending standards $z$ precisely when the pool is more adversely selected,

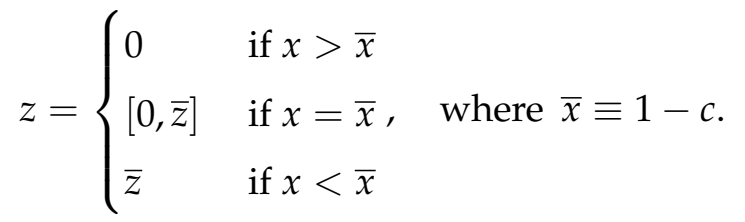

The combination of the two equations (8) and (9) is illustrated in Figure 1. Both represent downwardsloping relationships between $x$ and $z$, and given Assumption 2 admit three intersections, each of which represents a steady-state equilibrium. This logic is summarized in the following proposition.

Proposition 1 (Steady state equilibria). There exist three steady-state equilibria:

(i) A pooling steady state with $z=0$ and $x^{p}=\lambda$. 
(ii) A screening steady state with $z=\bar{z}$ and $x=x^{\mathcal{S}} \equiv \lambda-\lambda \frac{(1-\lambda) \bar{z}}{(1-\lambda \bar{z})+\delta \kappa^{-1}}$.

(iii) A mixed steady state with $z=\frac{\lambda-\bar{x}}{\lambda-\lambda \bar{x}}\left(1+\delta \kappa^{-1}\right) \in(0, \bar{z})$ and $x=\bar{x}$.

The root of the multiplicity is a dynamic strategic complementarity among banks. According to (9), banks naturally respond to a lower quality pool by tightening their lending standards; however, according to (8), tighter lending standards worsen the pool itself, creating an even bigger incentive for banks to tighten their standards in the future. This reasoning rationalizes the existence of the pooling and screening equilibria, see Figure 1. The mixed steady state formally exists but will turn out to be unstable and therefore play no role in the remainder of the analysis.

The pooling and screening steady states have the following important characteristics.

Corollary 1 (Quality of funded borrowers). $\quad$ 1. The credit spread $R$ is lower in the pooling steady state.

2. More projects are funded in the pooling steady state.

3. The default rate is higher in the pooling steady state.

The first point follows from the observation that a lower pool quality, ceteris paribus, hurts banks' profits, and therefore requires larger credit spreads for banks to break even. This is true, even if banks choose to screen more, in which case credit spreads rise partly due to greater screening costs. The second point follows from the fact that screening reduces the flow of borrowers that receive funding. The third point seems obvious, but really is not. In fact, when $\delta=0$ (no birth and death from the pool of potential borrowers), the default rate, defined as the share of type $L$ borrowers that receive funding, is equal to $1-\lambda$ in any steady state. Indeed, in the screening steady state, the imposition of tight lending standards exactly balances the low average project quality in the pool. This leads to the same share of bad projects being funded as in the pooling equilibrium. ${ }^{5}$

Corollary 1 gives the impression that tight lending standards cannot be social optimal. They are costly and may not improve the quality of funded borrowers while lowering the volume of funding. Yet, as the following section emphasizes, this is a dynamic model where transitions between steady states play a crucial rule.

\subsection{Transitional dynamics}

An important factor that simplifies the steady state analysis is the fact that banks are always active in a steady state, $\theta=1$. This is no longer true in equilibria with dynamics. In particular, there are now up to two regions in which banks may choose to remain inactive. Naturally, this is the case when the quality of the pool $x$ is very low, so that even a breakeven loan rate at its maximum of

\footnotetext{
${ }^{5}$ The results in Corollary 1 are robust to alternative assumptions on the dynamics of the borrower pool, e.g. assuming a constant inflow, rather than a constant pool size.
} 
Figure 2: State space and banks' optimal strategies.

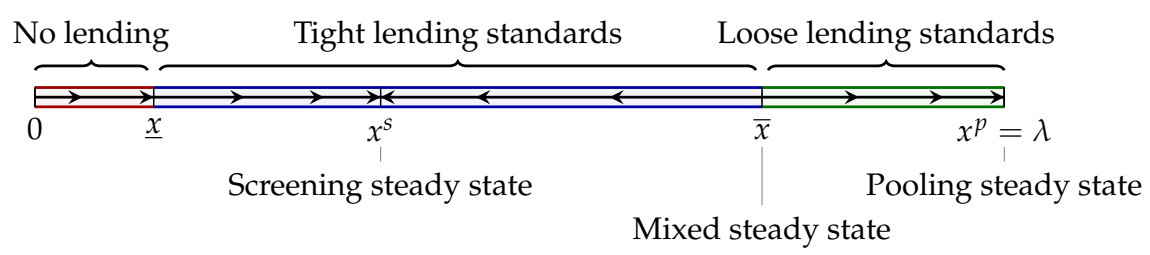

$R=V_{H}$ is not enough to recoup the losses incurred from lending to the many type- $L$ borrowers in the pool. Formally, this requires $x$ to be so low that $\Pi\left(V_{H}\right)<0$, or equivalently,

$$
\theta(x)=\left\{\begin{array}{ll}
0 & \text { if } x<\underline{x} \\
{[0,1]} & \text { if } x=\underline{x}
\end{array}, \quad \text { where } \underline{x} \equiv \frac{1-\bar{z}+c \bar{z}}{\rho-\bar{z}}\right.
$$

Somewhat more surprisingly, however, banks may also remain inactive in a subset of the pooling region, where inactivity can endogenously reduce the volume of lending and slow down the speed of convergence to the pooling steady state. We refer to this region as "slow-thawing" region and it is described in detail in Section 3.3. Until then, we assume parameters are such that there is no such region:

Assumption 3 (No slow thawing). Assume that there is no slow-thawing region, that is, $\theta(x)=1$ for all $x \in(\underline{x}, \lambda]$.

For the sake of exposition, this assumption is stated in terms of endogenous objects. The analytical condition is stated in the next section.

Under Assumption 3, the equilibrium transitional dynamics are as follows.

Proposition 2 (Transitional dynamics without slow thawing). Suppose Assumption 3 holds and $x_{0} \in[0, \lambda]$ is the initial fraction of type- $H$ borrowers in the pool. There is a unique equilibrium, in which banks' activity policy is given by (10), their lending standards are given by (9), and borrowers never wait, $\varphi_{t}^{a}=\varphi_{t}^{r}=1$. As $t \rightarrow \infty$, the credit market converges to

(i) the screening steady state, $x_{t} \rightarrow x^{s}$, if $x_{0}<\bar{x}$.

(ii) the mixed steady state, $x_{t} \rightarrow \bar{x}$, if $x_{0}=\bar{x}$

(iii) the pooling steady state, $x_{t} \rightarrow x^{p}$, if $x_{0}>\bar{x}$

Proposition 2 offers a full description of the equilibrium transitional dynamics. Strikingly, there is a unique equilibrium, despite the multiplicity of steady states (Proposition 1). This circumvents any interpretational difficulties due to equilibrium multiplicity and provides unambiguous model predictions. 
Figure 3: The self-reinforcing property of lending standards.

Quality of the pool $x$

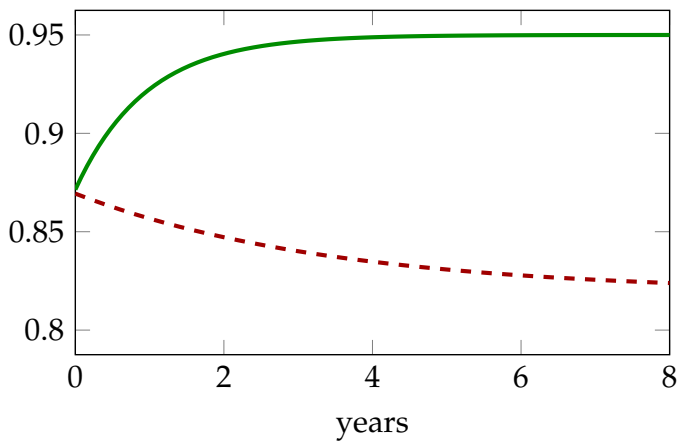

Lending volume

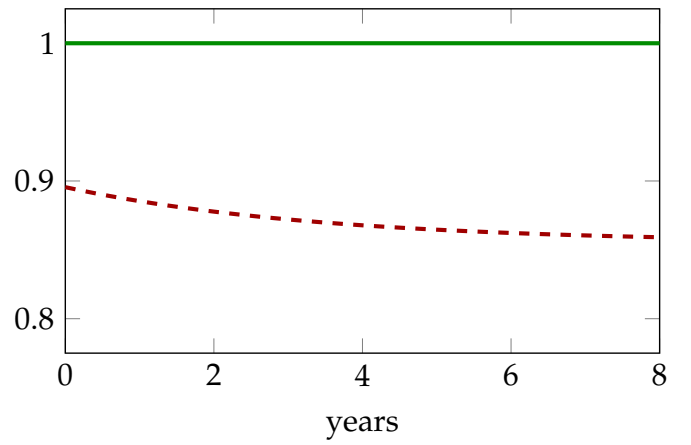

Credit spread $R$

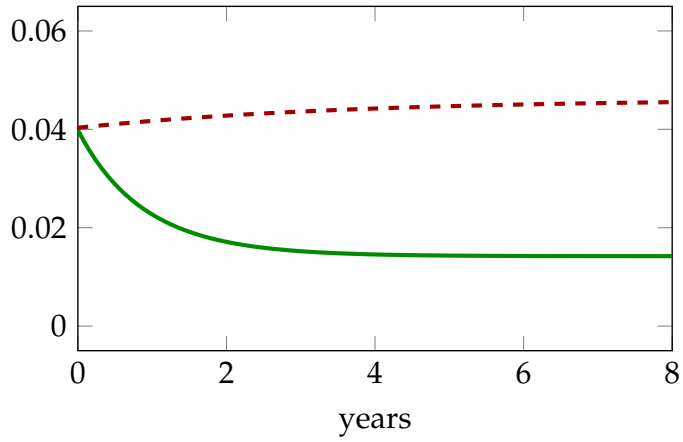

Quality of funded borrowers

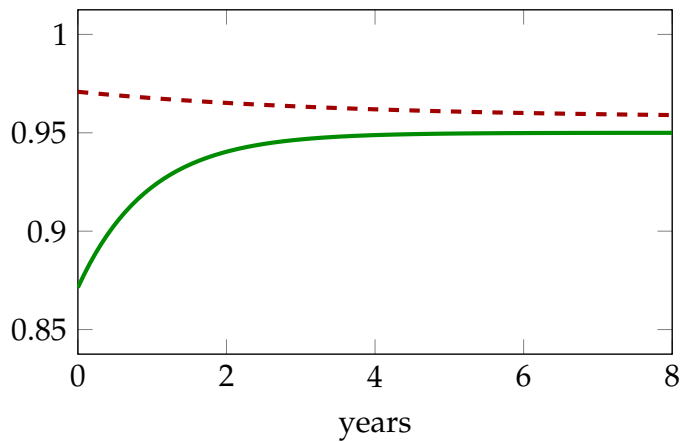

$-x_{0}>\bar{x} \quad---x_{0}<\bar{x}$

Note. This figure shows two sets of transitional dynamics in a credit market without slow thawing. Green and solid is a market starting at $x_{0}=\bar{x}+\epsilon$ and therefore banks have loose lending standards; red and dashed is a market starting at $x_{0}=\bar{x}-\epsilon$ and therefore banks impose tight lending standards. The parameters used for this simulation are as follows: TBD.

The model predictions can be seen in Figure 2, which illustrates the state space of the credit market and highlights the transitional dynamics in the three different regions of bank behavior: the "no lending" region for low pool qualities, where banks are inactive $\left(\theta_{t}=0\right)$ and the pool quality improves only due to death and birth; the "tight lending standards" region, where banks screen borrowers $z_{t}=\bar{z}$ and the market approaches the screening steady state; and the "loose lending standards" region where banks choose $z_{t}=0$ and the market returns to the pooling steady state.

A crucial part of the diagram is at $x=\bar{x}$. This point represents a sharp boundary between the tight and loose lending standards regions and gives rise to an important model prediction, a "bifurcation" property: when $x_{0}$ lies above $\bar{x}$, the credit market converges to the pooling steady state; when $x_{0}$ lies below $\bar{x}$, however, the self-reinforcing nature of tight lending standards push the market to the screening steady state.

The bifurcation property also comes out in Figure 3 where we simulate the credit market with 
Figure 4: Breakeven credit spread as function of pool quality $x$.

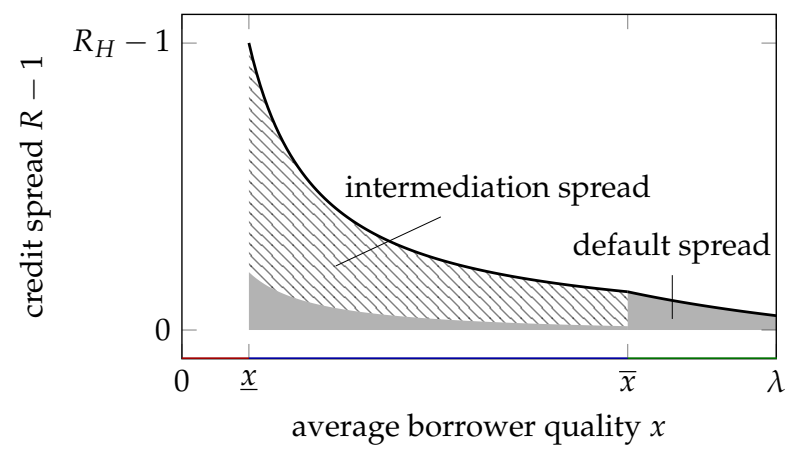

Note: Grey is the component of the credit spread that is due to default risk (the default spread). Hatched is the component of the credit spread that is due to intermediation costs (the intermediation spread).

two different initial values for $x_{0}$, one just above $\bar{x}$ (green, solid) and one just below $\bar{x}$ (red, dashed). As can be seen, this leads to a persistently different evolution of pool qualities $x$ and lending volumes $\kappa_{H t}+\kappa_{L t}(1-z)$.

Figure 3 also shows the evolution of the quality of funded borrowers, $\kappa_{H t} /\left(\kappa_{H t}+\kappa_{L t}(1-z)\right)$, for these two markets. The market with the relatively lower initial pool quality begins with a relatively higher quality of funded borrowers as banks are imposing tight lending standards. However, as shown by Corollary 1, this advantage vanishes asymptotically.

Ex-ante it may not seem obvious how equilibrium credit spreads compare across these credit markets. While a lower pool quality $x_{t}$ increases the breakeven rate, the banks' screening technology can initially lead to a better quality of funded borrowers. Yet, as the following proposition formally proves, $R_{t}$ is still inversely related to $x_{t}$.

Proposition 3 (Equlibrium credit spread). The equilibrium credit spread $R_{t}=R(x)$ is decreasing in the fraction of type- $H$ borrowers $x$ and is given by

$$
R_{t}=R(x)= \begin{cases}\infty & \text { if } x<\underline{x} \\ 1+\left(R_{L}-1\right) x^{-1}\{c \bar{z}+(1-\bar{z})(1-x)\} & \text { if } \underline{x} \leq x<\bar{x} \\ 1+\left(R_{L}-1\right) x^{-1}\{1-x\} & \text { if } x \geq \bar{x}\end{cases}
$$

Figure 4 plots the credit spread $R(x)$ over the state space, illustrating its inverse relationship with pool quality $x$. The monotonicity of $R(x)$ is the result of two offsetting forces. Using (11), we can decompose $R(x)-1$ into a default spread, $\left(R_{L}-1\right) x^{-1}(1-z(x))(1-x)$ where $z(x)$ is the optimal screening choice given $x$; and into an intermediation spread $\left(R_{L}-1\right) x^{-1} c z(x)$. The shaded areas in Figure 4 highlight that the default spread changes discretely at $x=\bar{x}$ as banks switch between screening and not screening, but this change is offset by an equally large change in the spread due to the costs of intermediation. The spread rises significantly due to intermediation costs at lower pool qualities $x$. 
The monotonicity of $R(x)$ is also reflected in Figure 3, with a rising loan rate for the credit market with the lower quality of potential borrowers and a falling loan rate for the market with higher quality. The falling loan rate raises an obvious question: wouldn't average borrowers have an incentive to wait for lower loan rates? The answer is yes in certain cases. Credit can be restricted even with loose lending standards, so that both lending volume and the improvement of the pool of borrowers are slowed, and credit markets recover ("thaw") much more slowly than otherwise.

\subsection{Slow thawing}

When $x_{0}$ is just above $\bar{x}$, it is possible that if $\theta_{t}=1$ and $R(x)$ were as defined in Proposition 3, then the increase in $x_{t}$ over time would lead to so rapid a decline in $R_{t}$ that average borrowers would strictly prefer not to accept loans but would instead prefer to wait for lower credit spreads $\left(\phi^{a}=0\right)$. This, however, would cause a market shutdown because no bank is willing to lend to rejected borrowers only, and therefore cannot be an equilibrium. Instead, the equilibrium must exhibit a slower speed of transition so that the improvement in the pool of potential borrowers and the decline in rates both occur more slowly and average borrowers are willing to accept loans in equilibrium. For this transition to be slower, it must be that not all banks are active $\left(\theta_{t}<1\right)$, which can only be the case if there are no profits to be made from making a new loan (see Definition 1). This is precisely the case when borrowers are also indifferent between waiting and applying for loans. The following proposition proves that these strategies are indeed an equilibrium.

Proposition 4 (Slow thawing). There exists a threshold $\hat{x} \in\left(0, x^{p}\right)$, such that: (i) if $\hat{x} \leq \bar{x}$, there is no slow thawing; if (ii) $\hat{x}>\bar{x}$, then for any $x \in[\bar{x}, \hat{x})$, a positive fraction of banks are inactive $\theta(x)<1$, where 6

$$
\theta(x)=\frac{(r+\delta)\left(R_{H}-R(x)\right)}{-\kappa R^{\prime}(x)(\lambda-x)}-\delta \kappa^{-1}
$$

where $R(x)=\left(R_{L}-1\right) x^{-1}\{1-x\}$. Borrowers are indifferent and apply for loans, $\varphi_{t}^{a}=\varphi_{t}^{r}=1$. $\hat{x}$ is determined as the unique solution to $\theta(\hat{x})=1$ in $\left(0, x^{p}\right)$.

The intuition for the expression in (12) comes directly from the indifference condition of average borrowers. Again, focus on the instructive special case where $u \rightarrow 0$. Then, the HJB of an average borrower is given by

$$
r J_{t}^{a}=\max _{\varphi_{t}^{a} \in[0,1]} \kappa \theta_{t} \varphi_{t}^{a}\left\{\lambda\left(R_{H}-R_{t}\right)-J^{a}\right\}+\dot{J}^{a}-\delta J^{a}
$$

with indifference between applying for a loan or not requiring that $J^{a}(x)=\lambda\left(R_{H}-R(x)\right)$. Substituting this back into the HJB yields an equation for the speed $\dot{x}$ at which the pool needs to improve

\footnotetext{
${ }^{6}$ For the sake of readability, we assume here that the utility benefit from running a project is comparatively small, $u \rightarrow 0$.
} 
Figure 5: Slowly thawing credit markets.

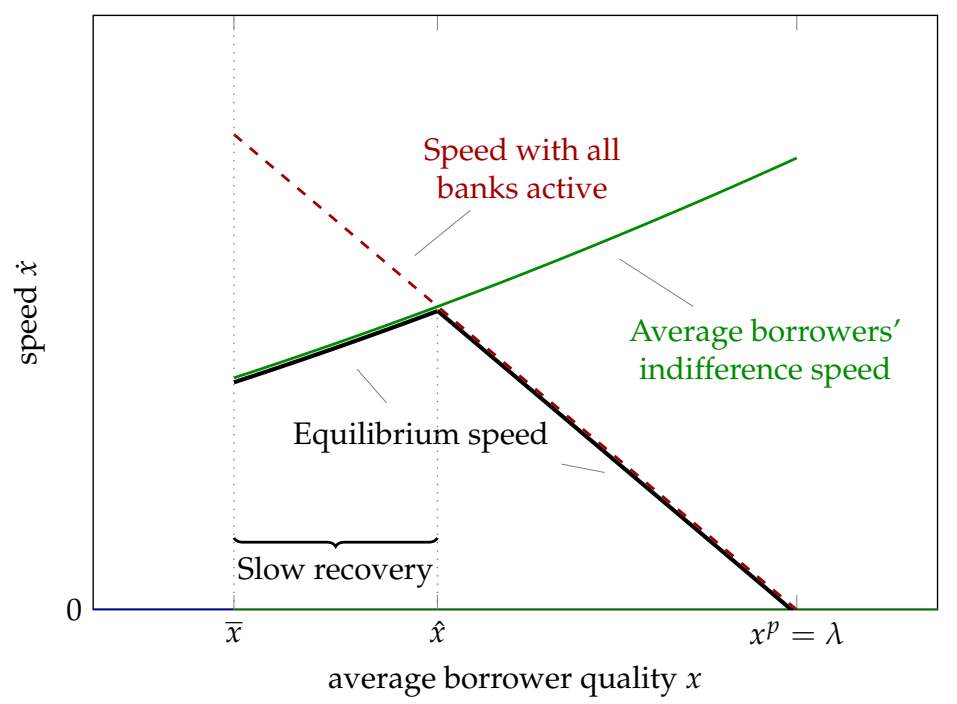

Note. This figure illustrates when there exists a region with "slow thawing" where credit markets recover only very slowly from a crisis. The green solid line represents the speed at which the pool quality needs to improve for average borrowers to be exactly indifferent between applying for loans (strictly preferred below the curve) and waiting (strictly preferred above). The red dashed line represents the speed of improvement when all banks are active. The equilibrium speed (black solid line) is the minimum of both curves.

for average borrowers to be indifferent,

$$
\underbrace{-\lambda R^{\prime}(x) \dot{x}}_{\text {benefit of waiting }}=\underbrace{(r+\delta) \lambda\left(R_{H}-R(x)\right)}_{\text {opportunity cost of waiting }} .
$$

When is $\dot{x}$ the equilibrium speed? Precisely when $\theta_{t}$ is such that $\dot{x}$ satisfies the law of motion of $x$, (6). Together, (13) and (6) give (12).

Figure 5 schematically illustrates this logic. The green solid line represents the speed $\dot{x}$ at which average borrowers are indifferent between borrowing now and waiting for the pool to improve. This is an increasing line as the benefit of waiting declines the closer $x$ is to the pooling steady state. The red dashed line represents the speed at which the pool quality improves when all banks choose to be active. Clearly, where this line falls in the "borrow" region, it is also equal to the equilibrium speed, shown in black solid. Where it is in the "wait" region, however, for $x<\hat{x}$, it cannot be an equilibrium. There, a fraction $1-\theta(x)$ of banks choose to be inactive, bringing down the equilibrium speed to match the one along the indifference curve. This leads to a hump-shaped thawing speed: a period of slow thawing due to the threat of average borrowers waiting followed by a period of normal convergence to the steady state.

What determines how likely or how strong this period of slow-down is? The following corollary reveals the roles of interest rates, project payoffs, and meeting frequencies. 
Corollary 2. Fix a quality of the borrower pool $x \in\left(\bar{x}, x^{p}\right)$ and let $\dot{x}$ denote the speed of improvement in the pool's quality. Then:

1. Worse projects slow down the recovery: $\dot{x}$ falls with lower $R_{L}, R_{H}$.

2. Low interest rates can backfire: if $x$ is in the slow-thawing region, $x<\hat{x}, \dot{x}$ falls with lower $r$.

3. Easy access to banks does not speed up the recovery: if $x$ is in the slow-thawing region, $x<\hat{x}$, greater meeting frequencies $\kappa$ do not raise $\dot{x}$; for $x>\hat{x}, \dot{x}$ rises with $\kappa$.

Most noteworthy are the comparative statics in 2 and 3. When $r$ (or $\delta$ ) is low, holding $R_{L}, R_{H}$ fixed, this effectively makes average borrowers more willing to wait, shifting down the indifference curve in Figure 5 and slowing down the recovery. This channel suggests that loose monetary policy can backfire, or at least be less effective, in aiding the recovery from a financial crisis.

When the meeting frequency $\kappa$ of borrowers and banks increases, the red line in Figure 5 increases. This naturally increases the speed of the recovery towards the steady state outside the slow-thawing region. Inside that region, however, it has no effect. In fact, even when $\kappa \rightarrow \infty$, the transition towards the pooling steady state is slow and entirely determined by the indifference condition (13).

Figure 6 juxtaposes the transitional dynamics with slow thawing (solid green line) and the transitional dynamics without slow thawing (dashed red line). The latter was computed assuming average borrowers do not have the option to wait therefore ruling out slow thawing. As is visible in the first panel, slow thawing can greatly slow the transition back to the pooling steady state and lead to a relatively low lending volume.

In closing, it is important to note that a similar region with slow thawing can also appear in the region between $\underline{x}$ and $x^{s}$ and slow down the convergence to the screening steady state from the left. Since our focus lies on the transitions between the pooling and screening steady states, we have relegated the characterization of that region to Appendix B.

\section{Efficiency}

At the heart of the positive model predictions is a dynamic strategic complementarity: when current banks operate tight lending standards and screen out low-quality borrowers, future banks prefer tight lending standards as well. We next characterize the (constrained) efficient outcomes. ${ }^{7}$

\footnotetext{
${ }^{7}$ The unconstrained efficient allocation (first-best) in our model would allow the planner to only fund average borrowers, which, given Assumption 2, he would do without screening.
} 
Figure 6: Slowly thawing credit markets.

Quality of the pool $x$

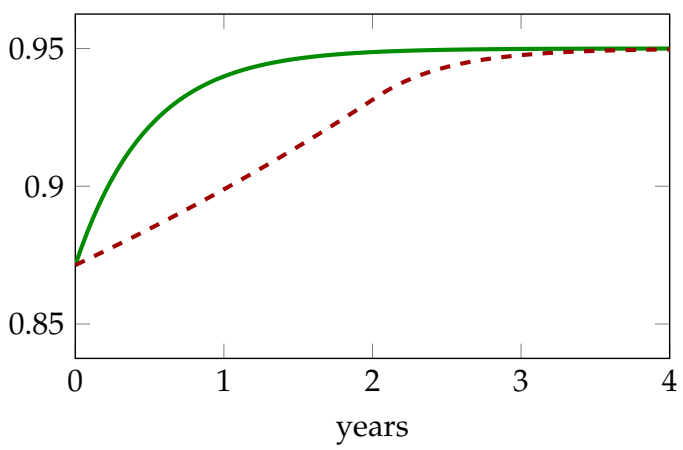

Lending volume

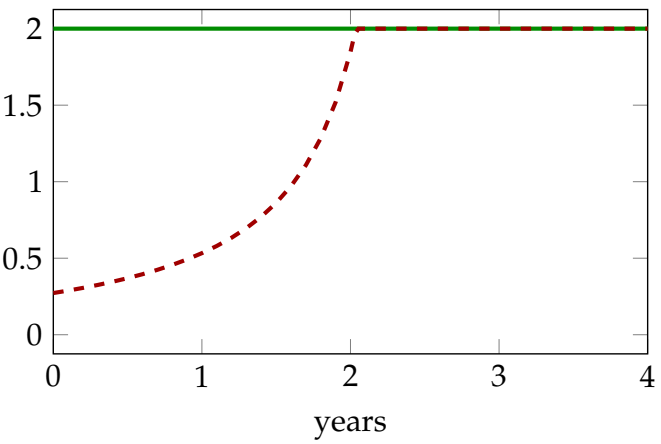

Credit spread $R$

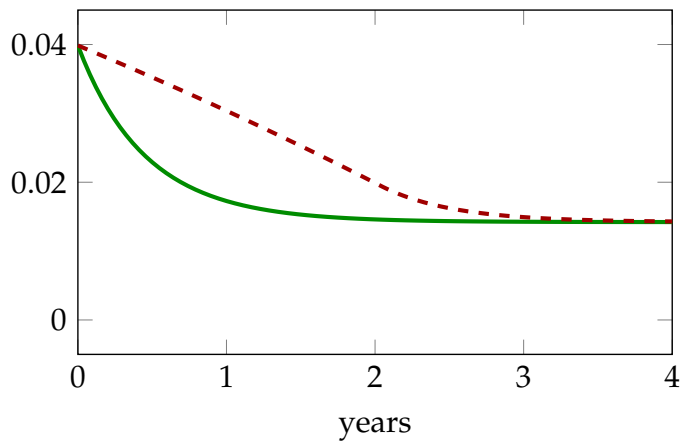

Quality of funded borrowers

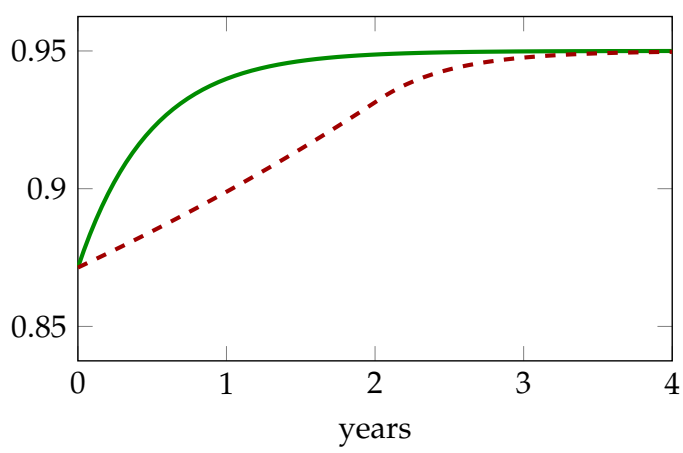

— without slow thawing - - - with slow thawing

Note. The plots compare two transitions back to the pooling steady state, one without a "slow thawing" region, and one with such a region. The parameters used for this simulation are: TBD. 


\section{Constrained efficient policy}

In our concept of constrained efficiency, we allow the planner to control banks' activity and screening decisions, subject to borrowers' application decisions, so as to maximize the sum of agents' utilities. ${ }^{8}$ To keep the exposition focused, we focus on the case where the private benefit from running the project $u$ is vanishingly small, $u \rightarrow 0$. In this section, it is further assumed that the planner can set the path of market interest rates, and therefore prevent type- $H$ borrowers from waiting (i.e. there is no slow thawing). We relax this assumption below.

The constrained efficient planning problem is then given by

$$
\max _{z_{t} \in[0, \bar{z}], \theta_{t} \in[0,1]} \int_{0}^{\infty} e^{-r t} \kappa \theta_{t}\left\{x_{t}\left(R_{H}-1\right)+\left(1-z_{t}\right)\left(1-x_{t}\right)\left(R_{L}-1\right)-\tilde{c} z_{t}\right\} d t
$$

subject to the law of motion of $x_{t},(6)$. The solution to this problem is given in the next proposition. Proposition 5 (Second-best policy). There exist thresholds $\underline{x}^{*}, \bar{x}^{*} \in[0, \bar{x})$ such that the second-best planner sets:

$$
\theta_{t}=\left\{\begin{array}{ll}
0 & \text { if } x_{t}<\underline{x}^{*} \\
1 & \text { if } x_{t}>\underline{x}^{*}
\end{array} \text { and } z_{t}= \begin{cases}\bar{z} & \text { if } x_{t}<\bar{x}^{*} \\
0 & \text { if } x_{t}>\bar{x}^{*}\end{cases}\right.
$$

Here, $\bar{x}^{*}$ is the largest $x$ that satisfies

$$
\begin{aligned}
& \underbrace{\frac{r x+\alpha^{s} x^{s}}{r+\alpha^{s}}\left(R_{H}-1\right)+(1-\bar{z})\left(1-\frac{r x+\alpha^{s} x^{s}}{r+\alpha^{s}}\right)\left(R_{L}-1\right)-\tilde{c} \bar{z}}_{\text {Average social benefit of screening }} \\
& \quad \underbrace{\frac{r x+\alpha^{p} x^{p}}{r+\alpha^{p}}\left(R_{H}-1\right)+\left(1-\frac{r x+\alpha^{p} x^{p}}{r+\alpha^{p}}\right)\left(R_{L}-1\right)}_{\text {Average social benefit of pooling }}
\end{aligned}
$$

where $\alpha^{p}=\kappa+\delta, \alpha^{s}=\kappa+\delta-\bar{z} \lambda \kappa$. In particular, for any $x_{t} \in\left(\bar{x}^{*}, \bar{x}\right)$, equilibrium lending standards are (second-best) inefficiently tight.

Proposition 5 reveals that the optimal policy is similar in spirit to the equilibrium: when the quality of the pool is relatively high, $x>\bar{x}^{*}$, loose lending standards, $z=0$, are optimal; when it is not, tight lending standards are optimal.

There is, however, one key distinction from the equilibrium dynamics: there exists a region in the state space where equilibrium lending standards are too tight relative to the second-best. To develop an intuition for this finding, imagine the current pool quality is $x$ and banks operate tight lending standards, $z=\bar{z}$, in all periods from now on. In this setting, the credit market ultimately converges to the screening steady state $x^{s}$ and one can think of $\frac{r x+\alpha^{s} x^{s}}{r+\alpha^{s}}$ as the time-averaged fraction of type- $H$ borrowers funded. The weight on $x$ is $r$ as with greater discounting the present becomes

\footnotetext{
${ }^{8}$ Since borrowers and banks are risk-neutral, this is without loss when the planner has access to transfers between agents.
} 
Figure 7: Constrained efficient vs. equilibrium lending standards.

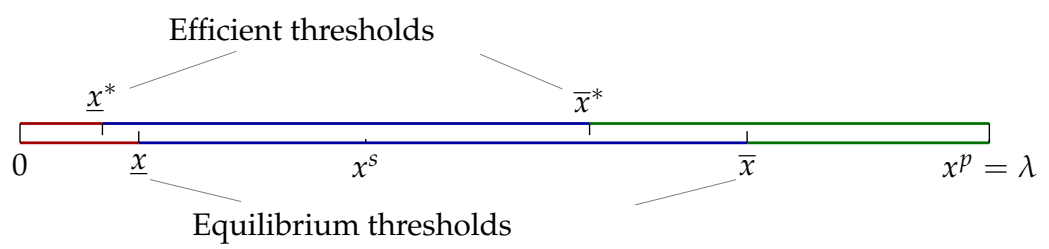

relatively more important. Vice versa, the weight on the steady state $x^{\mathcal{S}}$ is $\alpha^{\mathcal{S}}=\kappa+\delta-\bar{z} \lambda \kappa$, which is the speed at which $x$ converges to $x^{s}$. The average social benefit of screening is therefore

$$
\frac{r x+\alpha^{s} x^{s}}{r+\alpha^{s}}\left(R_{H}-1\right)+(1-z)\left(1-\frac{r x+\alpha^{s} x^{s}}{r+\alpha^{s}}\right)\left(R_{L}-1\right)-\tilde{c} \bar{z} .
$$

A similar expression describes the social benefit of pooling, giving rise to (16).

This stands in sharp contrast with the private trade-off, where $\bar{x}$ is the largest value satisfying

$$
\underbrace{x(R-1)+(1-\bar{z})(1-x)\left(R_{L}-1\right)-\tilde{c} \bar{z}}_{\text {Average private benefit of screening }} \geq \underbrace{x(R-1)+(1-x)\left(R_{L}-1\right)}_{\text {Average private benefit of pooling }}
$$

which is calculated using the current fraction $x$ of type- $H$ borrowers and entirely ignores the dynamic consequences from screening and pooling. In particular, since in the relevant region it holds that

$$
\frac{r x+\alpha^{s} x^{s}}{r+\alpha^{s}}<x<\frac{r x+\alpha^{p} x^{p}}{r+\alpha^{p}}
$$

agents privately ignore the dynamic costs from screening relative to pooling. Therefore, $\bar{x}^{*}<\bar{x}$. The private and social thresholds are shown in Figure 7.

Another way to highlight the differential dynamic consequences of pooling and screening is to compare steady states.

Corollary 3. The screening steady state has strictly lower welfare than the pooling steady state.

If $\delta=0$, this result would be a simple consequence of the fact that screening potential borrowers is costly and the quality of funded borrowers is independent of the steady state (Corollary 1). But with $\delta>0$, screening borrowers has a social benefit because a share of them are never funded. Nevertheless, Corollary 3 shows that this force is always less than the costs of screening and worse pool quality in steady state.

There are two important practical implications from the existence of a non-empty interval $\left(\bar{x}^{*}, \bar{x}\right)$ where the equilibrium diverges from the optimal allocation.

1. Intervention timing matters. Figure 8 simulates the characteristics of a credit market that starts at a given $x_{0} \in\left(\bar{x}^{*}, \bar{x}\right)$ for various times when an intervention starts (on the horizontal axis). The 
Figure 8: Early interventions dominate late ones.

Quality of the pool $x$ at intervention

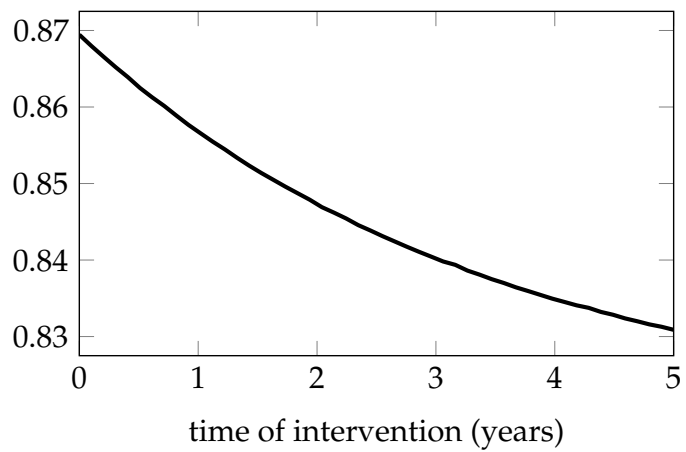

Welfare after intervention

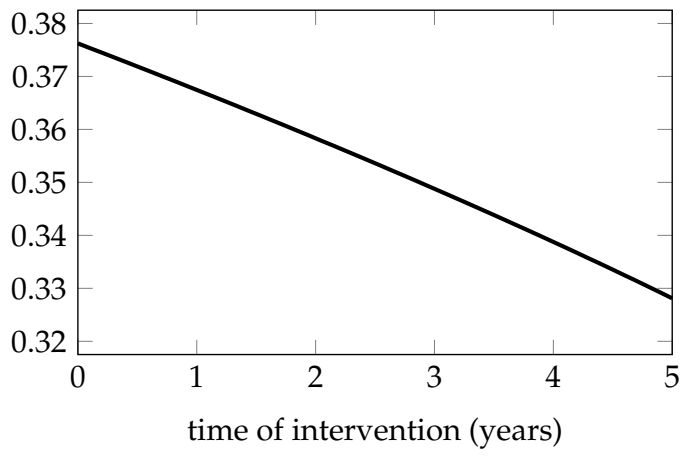

Note. This figure shows how intervention policies affect a credit market that is transitioning towards the screening steady state. The horizontal axis shows the time at which an intervention starts (where 0 corresponds to the immediate, constrained efficient intervention).

later the time of intervention is, the lower is the quality of the borrow pool when the policy switches from screening to pooling (left panel). Later intervention times thus increase the short-run losses incurred at the start of the intervention and are therefore welfare-inferior to early interventions. In fact, after a sufficiently long time, if $x_{t}$ has fallen below $\bar{x}^{*}$, intervening may even be welfaredominated by not intervening at all and allowing the market to converge to the screening steady state, despite its having lower welfare than the pooling steady state. That is, a late intervention may be worse than a policy of not intervening at all, a result that underscores the importance of the timing of interventions in our model. However, it may instead be the case that even at the screening steady state, it is still optimal to intervene and relax lending standards. In this case, intervention is always optimal (when the quality of the pool is weakly above that in the screening steady state).

2. Better screening technology may be detrimental to welfare. Suppose the cost $\tilde{c}$ of operating tight lending standards falls. While it is clear that such a reduction in costs necessarily raises efficiency in any steady-state equilibrium, it can decrease welfare because it raises both thresholds both for the market convergence to a screening equilibrium and for efficient intervention, both $\bar{x}$ and $\bar{x}^{*}$. Therefore, if a market is just recovering from a crisis, with $x_{0}$ just above $\bar{x}$, such a technological improvement may cause $\bar{x}$ to rise above $x_{0}$ and thereby prevent a recovery and lead to a reduction in welfare. If $x_{0}$ also rises above $\bar{x}^{*}$ then policy cannot mitigate this decline in welfare.

A decrease in costs $\tilde{c}$ represents an improvement in private information technology. What happens if instead public information technology (e.g. credit reporting) improves? We can capture this as an increase in $\delta$. Larger $\delta$ implies that borrowers die at a higher rate. While the death of average borrowers has no effect on equilibrium as they are replaced in the pool by an equal measure of new average borrowers, a greater death rate of rejected borrowers does matter for equilibrium. A larger $\delta$ raises the pool quality in the screening steady state, therefore unambiguously increasing welfare. Thus, the welfare effects of improving public information are unambiguously positive. 


\section{Constrained efficiency with slow thawing}

Suppose now there is a region with slow thawing, and the planner cannot influence loan rates $R_{t}$ directly. This corresponds to a planning problem with objective (14) subject to not only the law of motion of the state, (6), but also an average borrower's HJB equation (1a). Similar to the equilibrium analysis with slow thawing, this limits the speed of recovery as in (13). The characterization of the optimal policy in this case is a little more cumbersome. In effect, (15) still describes the optimal policy, except that $\theta(x)$ follows the equilibrium path (12) for $x \in\left[\bar{x}^{*}, \hat{x}\right)$.

\section{Implementation of the constrained optimum}

There are several ways in which a government or a regulating authority could implement the constrained efficient outcome, that is, looser lending standards when $x \in\left(\bar{x}^{*}, \bar{x}\right)$. Since such an intervention entails short-run losses (see Figure 8) and the model's banking sector is competitive, either the government or type- $H$ borrowers have to carry that burden. An example for a policy in the first category is a government-funded loan insurance limiting the exposure of banks to credit risk and reducing the need for tight lending standards. An example for a second-category policy is a simple tax on loan rejections by banks.

In contrast with these two policies, we now describe two examples of well-intended policies that could be problematic according to our model. First, consider the case where the bank operates one of the banks in the credit market and starts lending with loose standards. Unless the governmentowned bank has a significant market share, this will not suffice to cause $x$ to increase above $\bar{x}$ (where loose standards would be the equilibrium outcome). Instead, $x$ will continue to fall, albeit somewhat more modestly, as private banks continue to apply tight lending standards. This runs the risk of the government supporting type- $L$ borrowers at a time where the quality of the pool is already very low.

Second, as loan rates $R$ rise with lower pool qualities, governments may consider imposing caps on loan rates. In our stylized model of a credit market, this has severe effects. Not only does it not lead to the optimal policy (loose lending standards), it causes a lending freeze during which no bank finds it optimal to lend. Only after a while, as the pool naturally improves due to the entry of new borrowers and the exit of old ones, will banks resume lending.

\section{Discussion and Extensions}

In this section, we discuss the importance of a few of our assumptions and several extension of our model.

The first point to emphasize is that there are potential benefits of lending standards omitted from our model that may be pertinent in some lending markets. In particular, tight lending standards provide an incentive to improve quality along the dimension that is being evaluates. Thus tight standards could increase the average quality of new projects, as potential borrowers exert effort 
to avoid having type- $L$ projects. ${ }^{9}$ Under this assumption, tighter lending standards would have a positive externality: tighter standards today would increase the quality of the pool of potential borrowers for all banks in the future. This would provide a countervailing force to the effect of rejected borrowers in our model that would raise the relative efficiency of a steady state with screening.

Further, we note that tractability motivates some of our specific assumptions about the inflow of new potential borrowers. Our assumptions imply that the pool of potential borrowers has a constant size, which implies that $x$ is our sole state variable. One could instead for example assume that the inflow of new potential borrowers is constant, which would imply that the size of the pool would vary. While the choice of screening would still depend only on $x$, the dynamics of the market would in this alternative depend on the size of the pool as well as on $x$. While this would affect the dynamics of the market, this would not change many of the main lessons of the model, and in particular, the market would still exhibit two steady states (Corollary 1 would hold for a different range of parameter values) and the results on their relative efficiency, Corollary 3 derived in the next section, would still hold.

Turning to the banking sector, we have assumed that it is competitive so that banks make no profits in equilibrium. We conjecture that the qualitative features of the steady-states, dynamics and welfare results would all remain if banks shared the surplus of a match with a given potential borrower. The analysis is simplified by assuming that potential borrowers have all the bargaining power (or equivalently that banks compete by posting lending terms) as we have done.

Do our main results rely on our specific screening technology? For example, our screening technology never mistakes a type $H$ borrower for a type $L$ borrower. Such mistakes would imply that potential borrowers who are screened do not learn their type with certainty, and so there would be a distribution of beliefs among potential borrowers, with beliefs depending on the number of times a borrower had been screened and rejected for a loan. Such complexity would change the exact formula for $\dot{x}$. And it would complicate the analysis of the slow thawing region by potentially making possible regions with different speeds of slow thawing. Apart from this region however, since potential borrowers with different beliefs behave identically in the model (outside of any slow thawing region), our main results would remain intact.

Other changes to the screening technology are even less consequential. Our model can easily incorporate a screening technology is non-linear in cost. Concavity replicates our current results. Convexity would imply that rather than necessarily screening at a level of $\bar{z}$, banks might choose a lower level instead that equated marginal benefits of screening and marginal costs which would then necessarily depend on, and be increasing in, $x$. We have assumed that screening produces a binary signal, and it would be inconsequential to instead assume a continuous signal (banks would simply choose a cutoff value for their binary decision). Finally, if screening were correlated across banks, this would increase the strategic complementarity at the heart of our model since when one

\footnotetext{
${ }^{9}$ As noted earlier, $\mathrm{Hu}$ (2017) develops a model with this feature and studies its dynamics.
} 
bank screens and rejects a potential borrower, it makes it easier for the next bank to detect that borrower as bad and so raises the private value to screening.

We have discussed the model as model of lending with a debt contract. But in fact, in our model there is an equity contract that delivers exactly the same payoffs to banks and borrowers of each type. This equivalence arises because of the model has only two types of investors so that all good. With more types, our model could become significantly more complex in general. While the exact degree of complexity would depend on how well the screening technology detected different types, the extensions we have considered have all involved more state variables, which raises the possibility of non-linear dynamics that can occur in such systems.

\section{A credit boom-bust cycle}

One of the most salient features of the credit market is that it appears to come in "boom-bust cycles". Yet models of such behavior have proven elusive. We now argue that our model can give rise to such dynamics when we feed in a credit boom shock and study the optimal policy response to it.

\section{The credit boom}

We feed into the model a "market size shock" which allows a flow rate $\mu$ of new borrowers to enter the pool until time $T$. The new borrowers are assumed to have a lower fraction of type- $H$ borrowers, $\underline{\lambda}<\lambda$, capturing the idea that these are not borrowers that usually believe they are able to get a loan. Thus, the total size of the pool now evolves according to

$$
\dot{N}_{t}=\mu 1_{\{t \leq T\}}-\delta\left(N_{t}-1\right) \text {. }
$$

Our model in Section 2 involves a fixed pool size $N=1$ and therefore needs to be amended to allow for dynamics in $N$. However, as we show in Appendix XXX, since the law of motion of $N$ is entirely exogenous in the model, the model still applies to a "normalized" version of the credit market, where all absolute quantities (total volume of loans, total welfare, profit, etc) are to be thought of as normalized by $N$. The only adjustment that then needs to be made is that the fraction of type- $H$ borrowers, $x$, now evolves according to

$$
\dot{x}_{t}=\theta_{t} \kappa_{L t}\left(1-z_{t}\right) \lambda_{t}-\theta_{t} \kappa_{H t}\left(1-\lambda_{t}\right)+N_{t}^{-1}\left(\delta+\mu 1_{\{t \leq T\}}\right)\left(\lambda_{t}-x_{t}\right)
$$

where $\lambda_{t}$ is the average quality of new borrowers entering into the pool,

$$
\lambda_{t} \equiv \frac{\mu}{\mu+\delta} 1_{\{t \leq T\}} \underline{\lambda}+\frac{\delta}{\mu+\delta} \lambda
$$

For the simulations in this section, we calibrate the model parameters as follows: TBD. Under this parameterization, the market turns out not to have a region with slow thawing. 
Figure 9: The boom-bust cycle.

Quality of the pool $x$

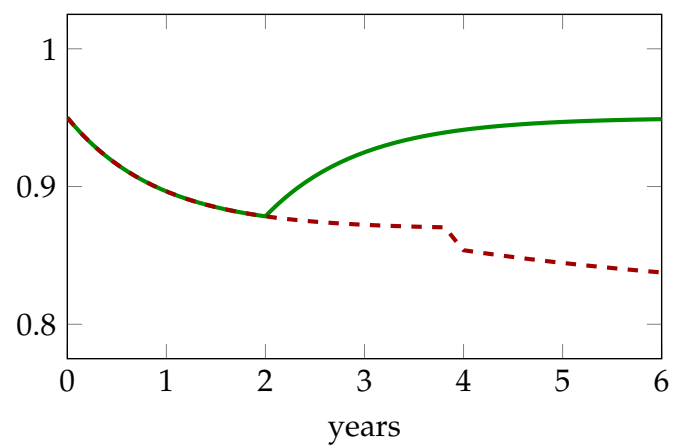

Lending volume

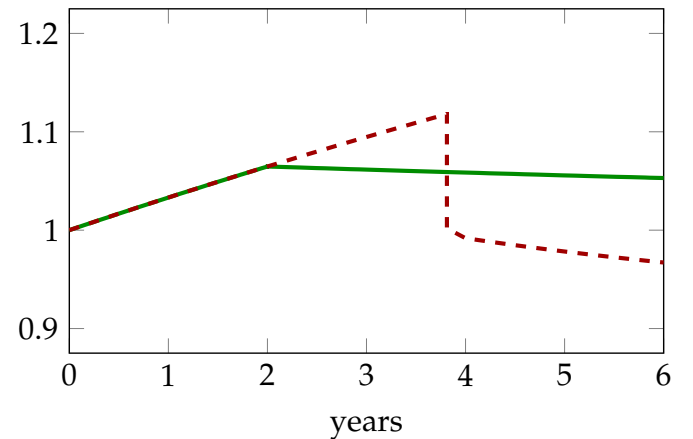

Loan rate $R$

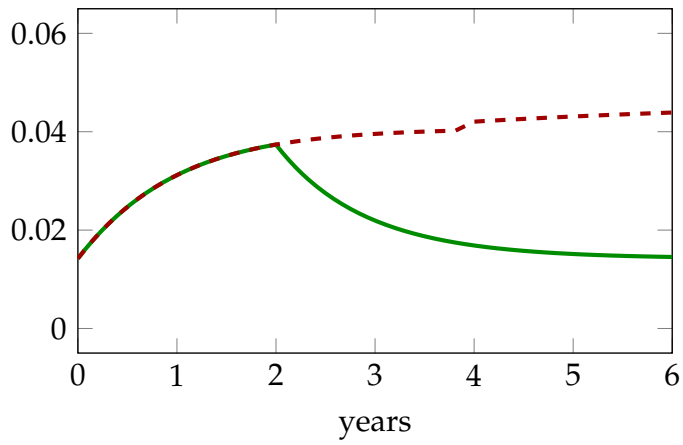

Quality of funded borrowers

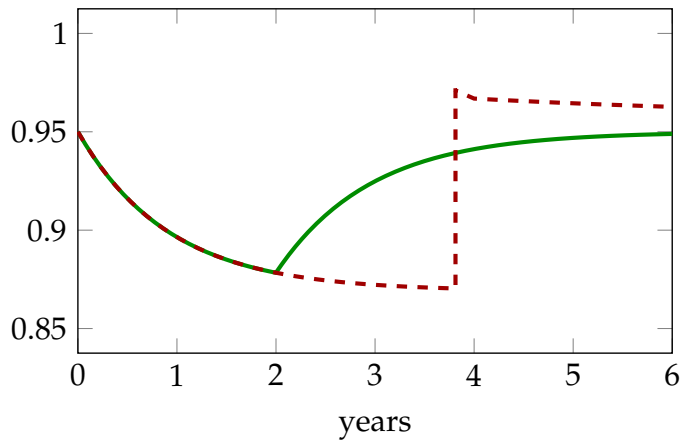

_ short boom - - - long boom

Note. This figure shows a credit market in response to two shocks: the green solid line represents a 2-year credit boom, the red dashed line a 4-year credit boom. A "credit boom" is modeled as an inflow of relatively less creditworthy borrowers. The transitions were computed using these parameters: TBD.

\section{The boom-bust cycle}

We simulate the response to two different boom lengths, with $T_{0}=2$ years and $T_{1}=4$ years. The results are shown in Figure 9. As the solid green line shows, the short boom goes hand in hand with an increasing lending volume and a decline in the quality of borrowers, and ends in a soft decline ultimately converging back to the original steady state. Contrast this with the long boom (dashed red line). This boom ends in an abrupt decline in volume, an increase in lending standards, and a permanent transition away from the original steady state.

\section{Policy response}

\section{Conclusion}

[to be written] 


\section{References}




\section{A Proofs and derivations}

\section{A.1 Steady state equilibria: Proof of Proposition 1}

The three pairs $(x, z)$ mentioned in Proposition 1 are solutions to (8) and (9) if $\lambda>\bar{x}, x^{\mathcal{S}}<\bar{x}$,

and $\frac{\lambda-\bar{x}}{\lambda-\lambda \bar{x}}\left(1+\delta \kappa^{-1}\right)<\bar{z}$. The first two of these hold by Assumption 2 and the third is a straight consequence of the second.

We claim that the three pairs indeed constitute equilibria, with $\theta=1, \varphi^{a}=\varphi^{r}=1$ and with $R$ pinned down by Proposition 3. To prove this, first note that the law of motion (6) as well as the bank's maximization problem (4) are satisfied due to (8) and (9). The zero profit condition (5) pins down the interest rate (see our proof to Proposition 3). Finally, in any steady state the average borrower strictly prefers a loan today, that is,

$$
\lambda\left(R_{H}-R+u\right)+(1-\lambda)(1-z) u+(1-\lambda) z J^{r}-J^{a}>0
$$

and since $R \leq R_{H}$ (which holds since $x^{\mathcal{S}} \geq \underline{x}$ with $\underline{x}$ as in (10) due to Assumption 2) we have that $\theta=1$ and $\varphi^{a}=\varphi^{r}=1$.

\section{A.2 Proof of Corollary 1}

The flow of projects being funded in the pooling steady state is $\kappa$, compared to $\kappa x^{\mathcal{S}}+\kappa\left(1-x^{\mathcal{S}}\right)(1-\bar{z})$ in the screening steady state. The credit spread result follows directly from Proposition 3 and the fact that $R(x)$ is strictly decreasing in $x$. The equilibrium default rate is given by

$$
\frac{\kappa(1-x)(1-z)}{\kappa(1-x)(1-z)+\kappa x}=\left(1+\frac{x}{(1-x)(1-z)}\right)^{-1}
$$

which can further be simplified to

$$
(1-\lambda)\left(1+\frac{\lambda z \delta \kappa^{-1}}{\left(1+\delta \kappa^{-1}\right)(1-z)}\right)^{-1} .
$$

Thus, when $\delta=0$, the equilibrium default rate is always equal to $1-\lambda$, irrespective of the steady state.

\section{A.3 Proof of Proposition 2}

Let $x_{0} \in[\underline{x}, \bar{x})\left(x_{0} \in(\bar{x}, \lambda]\right)$. In that case, $z=\bar{z}(z=0)$ is the optimal bank strategy (see (4)), and therefore the law of motion of $x,(6)$, necessarily describes the unique equilibrium dynamics of $x$. By Assumption 6, $\theta_{t}=1$ and therefore also $\varphi_{t}^{a}=1=\varphi_{t}^{r}$ (due to (7)).

The case $x_{0}=\bar{x}$ is straightforward as $\bar{x}$ is a steady state.

Finally, if $x<\underline{x}, R(x)=\infty$, which is why the only possible equilibrium involves $\theta_{t}=0$. In that 
region, therefore, the pool improves according to $\dot{x}_{t}=\delta\left(\lambda-x_{t}\right)$, until $x$ hits $\underline{x}$, in which case the law of motion switches to be the same as the one for an initial quality $x_{0} \in[\underline{x}, \bar{x})$.

\section{A.4 Proof of Proposition 3}

The zero profit condition (5) implies that

$$
\Pi(R)=\kappa_{H}(R-1)+\kappa_{L}(1-z)\left(R_{L}-1\right)-\left(\kappa_{H}+\kappa_{L}\right) \tilde{c} z=0 .
$$

Reformulating this we obtain

$$
\begin{gathered}
\kappa x(R-1) /\left(R_{L}-1\right)+\kappa(1-x)(1-z)+\kappa c z=0 \\
R=1+\left(1-R_{L}\right) \frac{c z+(1-x)(1-z)}{x}
\end{gathered}
$$

which proves Proposition 3.

\section{A.5 Proof of Proposition 4}

Define $\theta(x)$ as in (12) and define $\hat{x}$ implicitly as the unique value of $x<\lambda$ with $\theta(x)=1$. Such a value exists since $\theta(x)$ is strictly increasing and continuous in $x$ with $\theta(0)=-\delta \kappa^{-1}<0$ and $\lim _{x \rightarrow \lambda} \theta(x)=\infty$.

Assume $\hat{x}>\bar{x}$. Conjecture for any $x_{0} \in[\bar{x}, \hat{x})$ that the equilibrium is one with $\theta_{t}=\theta\left(x_{t}\right)$. To verify the conjecture, we need to show that average borrowers are indifferent between taking a loan and waiting. Assuming $u \rightarrow 0$ in (1a), this is equivalent to

$$
J_{t}^{a}=\lambda\left(R_{H}-R\left(x_{t}\right)\right)
$$

with

$$
r J_{t}^{a}=\dot{J}_{t}^{a}-\delta J_{t}^{a}
$$

Putting the two together, we obtain (13),

$$
-\lambda R^{\prime}(x) \dot{x}=(r+\delta) \lambda\left(R_{H}-R(x)\right) .
$$

The law of motion for $x$ with $\theta<1$ is $\dot{x}_{t}=(\kappa \theta+\delta)(\lambda-x)$, which, together with (13) yields (12) and therefore confirms that average borrowers are, by construction, precisely indifferent.

\section{A.6 Proof of Proposition 5}

We prove Proposition 5 in two steps. First, we determine the efficient screening policy $z^{*}(x)$. To do so, let $V(x, z)$ denote the present value of welfare if the current state of the market is $x$ and the 
screening policy is $z$ from hereafter, that is,

$$
V(x, z) \equiv \frac{r x+\alpha^{z} x^{z}}{r+\alpha^{z}}\left(R_{H}-1\right)+(1-z)\left(1-\frac{r x+\alpha^{z} x^{z}}{r+\alpha^{z}}\right)\left(R_{L}-1\right)-\tilde{c} z .
$$

where $\alpha^{z} \equiv \kappa+\delta-\lambda \kappa z$ and $x^{z} \equiv \lambda-\lambda \frac{(1-\lambda) z}{(1-\lambda z)+\delta \kappa^{-1}}$. Also, denote by

$$
v(x, z) \equiv r\left\{x\left(R_{H}-1\right)+(1-z)(1-x)\left(R_{L}-1\right)-\tilde{c} z\right\}
$$

the flow value of policy $z$ at state $x$. Finally, we call

$$
d(x, z) \equiv \kappa(1-x)(1-z) \lambda-\kappa x(1-\lambda)+\delta(\lambda-x)
$$

the derivative of $x$ at state $x$ under policy $z$ (see the law of motion in $(\mathrm{XXX})$ ). Observe that

$$
r V(x, z)=v(x, z)+V_{x}(x, z) d(x, z)
$$

as well as

$$
d\left(x^{s}, \bar{z}\right)=0 d\left(x^{p}, 0\right)=0 .
$$

We first prove the following helpful lemma.

Lemma 1. We have:

1. If $\lambda \kappa \rho \geq r+\kappa+\delta$, pooling is strictly optimal for any state $x$, i.e. $z^{*}(x)=0$.

2. If $\lambda \kappa \rho<r+\kappa+\delta, V(x, z)$ has negative cross-partials, $V_{x z}<0$.

3. If $\lambda \kappa \rho<r+\kappa+\delta$ and $V(x, 0)>V\left(x, z_{1}\right)$ for some $z_{1}>0$, then also $V(x, 0)>V\left(x, z_{2}\right)$ for any $z_{2} \in\left(0, z_{1}\right)$.

Proof. Assume $\lambda \kappa \rho \geq r+\kappa+\delta$. Suppose pooling were not strictly optimal for every state $x$. First, if $d\left(x, z^{*}(x)\right)$ is ever non-negative for some $x<\lambda$, there must be a steady state at some $x^{0} \in[0, \lambda)$ with some $z^{*}\left(x^{0}\right)>0$. This cannot be optimal since

$$
V\left(x^{0}, z^{0}\right)<V\left(x^{0}, 0\right)
$$

is equivalent to (after a few lines of algebra)

$$
-\left(r+(1-\lambda) \alpha^{p}-r x^{0}\right)(\rho \kappa \lambda-(r+\kappa+\delta))<\left(r+\alpha^{s}\right)\left(r+\alpha^{p}\right) c
$$

which is true since the left hand side is negative. Second, assume $d\left(x, z^{*}(x)\right)$ is positive everywhere. Then, $x^{p}=\lambda$ is still the unique steady state. Let $\mathbf{V}(x)$ the optimal value function. It has to hold that

$$
r \mathbf{V}(x)=v\left(x, z^{*}(x)\right)+\mathbf{V}^{\prime}(x) d\left(x, z^{*}(x)\right)
$$




\section{Rearranging,}

$$
\mathbf{V}^{\prime}(x)=\frac{r \mathbf{V}(x)-v\left(x, z^{*}(x)\right)}{d\left(x, z^{*}(x)\right)} \equiv \mathbf{F}(\mathbf{V}(x), x)
$$

Compare this to the ODE describing the value of pooling,

$$
V_{x}(x, 0)=\frac{r V(x, 0)-v(x, 0)}{d(x, 0)}=\mathbf{F}^{0}(V(x, 0), x)
$$

Observe that $\mathbf{F}(V, x)>\mathbf{F}^{0}(V, x)$ for any $x$ for which $z^{*}(x)>0 .{ }^{10}$ Since $\mathbf{V}\left(x^{p}\right)=V\left(x^{p}, 0\right)$, it must be that $\mathbf{V}(x)<V(x, 0)$ for $x$ sufficiently small. This contradicts our assumption that $\mathbf{V}(x)$ is the optimal value function. Thus, pooling is optimal for every state.

Assume $\lambda \kappa \rho<r+\kappa+\delta$. Simple algebra based on (19) implies that

$$
V_{x}=\frac{r}{r+\alpha^{z}}\left(R_{H}-1\right)+(1-z) \frac{r}{r+\alpha^{z}}\left(1-R_{L}\right)>0
$$

and

$$
V_{x z}=r \frac{\lambda \kappa \rho-(r+\kappa+\delta)}{\left(r+\alpha^{z}\right)^{2}\left(1-R_{L}\right)}<0
$$

With this result in mind, we can characterize $z^{*}(x)$.

Lemma 2. Assume $\lambda \kappa \rho<r+\kappa+\delta$. The efficient screening policy $z^{*}(x)$ is to screen if $x<\bar{x}^{*}$ and to pool if $x>\bar{x}^{*}$, where

$$
V\left(\bar{x}^{*}, 0\right)=V\left(\bar{x}^{*}, \bar{z}\right)
$$

as long as the solution to that equation is greater or equal to $x^{s}$. Otherwise, $\bar{x}^{*}$ is determined by

$$
v_{z}\left(\bar{x}^{*}, 0\right)+V_{x}\left(\bar{x}^{*}, 0\right) d_{z}\left(\bar{x}^{*}, 0\right)=0 .
$$

Proof. First, notice that $\bar{x}^{*}$ is indeed well-defined, in that if the solution to (23) is $x^{\mathcal{S}}$, then (24) is also solved by $x^{s}$. Assume

$$
V\left(x^{s}, 0\right)=V\left(x^{s}, \bar{z}\right)
$$

Combining (20) and (21), we can rewrite $V\left(x^{\mathcal{s}}, 0\right)$ and $V\left(x^{\mathcal{s}}, \bar{z}\right)$ and obtain

$$
v\left(x^{s}, 0\right)+V_{x}\left(x^{s}, 0\right) d\left(x^{s}, 0\right)=v\left(x^{s}, \bar{z}\right)+V_{x}\left(x^{s}, \bar{z}\right) d\left(x^{s}, \bar{z}\right) .
$$

Since $d\left(x^{s}, \bar{z}\right)=0$, this can be combined into

$$
v\left(x^{s}, \bar{z}\right)-v\left(x^{s}, 0\right)+V_{x}\left(x^{s}, 0\right)\left(d\left(x^{s}, \bar{z}\right)-d\left(x^{s}, 0\right)\right)=0
$$

\footnotetext{
${ }^{10}$ Note that $\mathbf{V}^{\prime}(x)>0$ by a simple envelope argument.
} 
which is equivalent to (24) as $v$ and $d$ are linear in $z$. Moreover, going these steps backwards, if $\bar{x}^{*}<x^{s}$, then (25) holds with inequality and therefore

$$
V\left(x^{s}, 0\right)>V\left(x^{s}, \bar{z}\right)
$$

Now we proceed to our main argument, a proof by contradiction. We distinguish four possible cases.

Case 1: There exists $x>\bar{x}^{*}$ with $x \geq x^{s}$ where screening is optimal. If true, this would require there to be at least one point $x^{0} \in\left[\bar{x}^{*}, \lambda\right)$ where the planner strictly prefers to remain at $x^{0}$ forever (by choosing strategy $z^{0} \in(0, \bar{z}]$ such that $d\left(x^{0}, z^{0}\right)=0$ ) over pooling. In math,

$$
V\left(x^{0}, z^{0}\right)>V\left(x^{0}, 0\right)
$$

Since $V$ has a negative cross-partial $V_{x z}<0$ (Lemma 1), this implies that $V\left(\bar{x}^{*}, z^{0}\right)>V\left(\bar{x}^{*}, 0\right)$ and $V\left(x^{s}, z^{0}\right)>V\left(x^{s}, 0\right)$, which, by point 3 in Lemma 1 , is contradicting either (23) or (26).

Case 2: There exists $x<\bar{x}^{*}$ with $x \geq x^{s}$ where pooling is optimal. If true, this would require there to be at least one point $x^{0} \in\left(x^{s}, \bar{x}^{*}\right]$ where the planner strictly prefers to remain at $x^{0}$ forever (by choosing strategy $z^{0} \in[0, \bar{z})$ such that $d\left(x^{0}, z^{0}\right)=0$ ) over screening. In math,

$$
V\left(x^{0}, z^{0}\right)>V\left(x^{0}, \bar{z}\right)
$$

Since $V$ has a negative cross-partial $V_{x z}<0$ (Lemma 1), this implies that $V\left(\bar{x}^{*}, z^{0}\right)>V\left(\bar{x}^{*}, \bar{z}\right)$, which by point 3 in Lemma 1, contradicts (23).

Case 3: There exists $x>\bar{x}^{*}$ with $x \leq x^{s}$ where screening is optimal. If true, this would require there to be at least one point $x^{0} \in\left[\bar{x}^{*}, x^{s}\right]$ where the planner strictly prefers to screen with some intensity $z^{0}>0$ in the current instant while pooling is chosen thereafter. That is,

$$
v\left(x^{0}, z^{0}\right)+V_{x}\left(x^{0}, 0\right) d\left(x^{0}, z^{0}\right)>v\left(x^{0}, 0\right)+V_{x}\left(x^{0}, 0\right) d\left(x^{0}, 0\right) .
$$

Due to linearity of this equation, it also has to hold with $z^{0}=\bar{z}$, and therefore also expressed as derivative,

$$
v_{z}\left(x^{0}, 0\right)+V_{x}\left(x^{0}, 0\right) d_{z}\left(x^{0}, 0\right)>0 .
$$

Since this is a linear equation in $x^{0}$, to be consistent with (24), it must be that (27) in fact holds for any $x^{0}>\bar{x}^{*}$, including $x^{0}=x^{p}=\lambda$. In that case, however, (27) simplifies to $v_{z}\left(x^{p}, 0\right)+$ $V_{x}\left(x^{p}, 0\right) d_{z}\left(x^{p}, 0\right)>0$, which is false, since $V_{x}(x, 0)>0, d_{z}(x, 0)<0$ and $v_{z}\left(x^{p}, 0\right)=-\kappa(1-$ $\left.R_{L}\right)(c-(1-\lambda))<0$ by Assumption 2. 
Case 4: There exists $x<\bar{x}^{*} \leq x^{\mathcal{S}}$ where pooling is optimal. Let $\mathrm{V}(x)$ be our conjectured value function left of $\bar{x}^{*}$. By design, $\mathrm{V}(x)$ solves

$$
r \mathbf{V}(x)=v(x, \bar{z})+\mathbf{V}^{\prime}(x) d(x, \bar{z})
$$

where $d(x, \bar{z})=\alpha^{\bar{z}}\left(x^{\mathcal{S}}-x\right)$ and $\mathbf{V}^{\prime}(x)$ solves

$$
\left(r+\alpha^{\bar{z}}\right) \mathbf{V}^{\prime}(x)=v_{x}(x, \bar{z})+\mathbf{V}^{\prime \prime}(x) d(x, \bar{z})
$$

This ODE can be solved explicitly, giving ${ }^{11}$

$$
\mathbf{V}^{\prime}(x)=A\left(x^{s}-x\right)^{-\beta}+\frac{v_{x}(x, \bar{z})}{r+\alpha^{\bar{z}}} \equiv f_{1}(x)
$$

where $\beta=1+\frac{r}{\alpha^{z}}$ and $A \in \mathbb{R}$ is a parameter to fit the boundary condition $\mathbf{V}^{\prime}\left(\bar{x}^{*}\right)=V_{x}\left(\bar{x}^{*}, 0\right)$.

Could it ever be that the planner prefers pooling in this region? If so, we would have to have for some $x<\bar{x}^{*}$ that

$$
v(x, \bar{z})+\mathbf{V}^{\prime}(x) d(x, \bar{z})<v(x, 0)+\mathbf{V}^{\prime}(x) d(x, 0)
$$

which is equivalent to

$$
\mathbf{V}^{\prime}(x)<\frac{r\left(1-R_{L}\right)}{\kappa \lambda}-\frac{r \tilde{c}}{\kappa \lambda(1-x)} \equiv f_{2}(x) .
$$

Notice that $f_{1}(x)$ and $f_{2}(x)$, which intersect at $x=\bar{x}^{*}$ can only have a single intersection since ... to be continued.

\section{A.7 Derivation of law of motion for credit boom shock}

tbd

\section{A.8 Constrained efficiency with slow thawing \\ tbd}

\section{B Slow thawing during convergence to screening steady state}

tbd

\footnotetext{
${ }^{11}$ Note that $v_{x}(x, \bar{z})$ is a constant in $x$.
} 